\title{
A RACIONALIDADE ESCOLAR EM QUESTÃO: os trabalhos de memória em educação
}

\section{Maria Regina Clivati Capelo}

Professora do Depto. de Ciências Sociais da Universidade Estadual de Londrina.

Partindo de uma análise crítica sobre a racionalidade que caracteriza os fazeres e saberes escolares, o texto tem o objetivo de demonstrar a positividade da inserção dos trabalhos de memória nas práticas de ensino da escola fundamental. Para tanto, apresenta uma discussão sobre a relação entre memória e educação compondo uma base sobre a qual se fundamenta o relato de uma experiência efetiva que transformou os recursos metodológicos da pesquisa histórica e sociológica em uma metodologia de ensino.

INTRODUÇÃO

V ivenciando o ambiente escolar somos continuamente instigados a procurar respostas para os dilemas do presente mas, nem sempre essa procura extrapola a crítica e a indignação. Este ensaio constitui uma primeira tentativa de associar uma crítica fundamentada teoricamente à indicação de uma, entre muitas possibilidades, para o redimensionamento da atividade pedagógica.

A análise empreendida na primeira parte toma o fio condutor da racionalidade escolar enfocada como síntese do paradigma cartesiano, que orienta o fazer científico atual, agora questionado quanto ao seu caráter paradoxal, em face de uma realidade social impregnada por outras racionalidades ignoradas por essa epistemologia científica. Assim, pode-se dizer que a parte introdutória deste ensaio é simultaneamente uma auto-crítica forjada a partir das contradições experienciadas no cotidiano escolar e estruturada à luz de reflexões teóricas, e ainda, um anúncio sobre a necessidade de refazer o passado para repensar o presente escolar.

Nessa perspectiva, a segunda parte enfoca a positividade dos trabalhos de memória no campo escolar, como uma alternativa que pode ser o ponto de partida para romper a inércia pedagógica ensimesmada numa teia circular de queixas e reclamações. De uma prática escolar simplificadora e previamente planejada, propõe-se uma certa desordem na ordem didática integrando crianças e velhos no processo de socialização do conhecimento.

Três momentos precisos e distintos caracterizam a segunda parte: o primeiro reporta-se às sociedades sem escrita para buscar referências acerca do sentido educativo que a memória oral adquire na configuração do devir histórico e também em aspectos que podem ter significados para a compreensão da educação escolar nas sociedades complexas. $\mathrm{O}$ segundo focaliza a relação entre memória e história insinuando, de modo ainda precário, a diferenciação memória escolar e história da educação. Finalmente, no terceiro momento, consta o breve relato de uma experiência de recuperação da memória de uma escola rural que envolveu os próprios escolares no processo, transformando a metodologia de pesquisa da história oral em metodologia de ensino.

\section{PARTE - A RACIONALIDADE ESCOLAR EM QUESTÃO}

“ORA, EU CREIO PROFUNDAMENTE QUE NÓS VIVEMOS COM PRINCÍPIOS QUE INDENTIFICAMOS DE FORMA ABSOLUTA COM A CIÊNCIA E QUE DE FACTO, CORRESPONDEM A SUA IDADE "CLÁSSICA" DO SÉCULO XVIII AO FIM DO SÉCULO XIX, E SÃO ESSES PRINCÍPIOS QUE DEVEM SER TRANSFORMADOS “. (Edgar Morin)

Partindo de uma análise crítica do paradigma científico clássico, MORIN (1990) aceita o desafio de pensar e reconhecer as complexidades da própria ciência e da realidade, propondo a superação do sistema parcelar em favor de uma perspectiva universalista da condição humana e da sociedade. Trata-se de uma ciência com consciência que implica na necessária reflexão a respeito dos usos que são feitos do saber científico, nem sempre ligados às necessida- 
des sociais e ao controle ético da própria atividade científica.

"A ciência é um assunto demasiado sério para ser entregue unicamente nas mãos dos cientistas. Mais, eu diria que a ciência se tornou demasiada perigosa para ser entregue nas mãos dos homens de Estado $e$ dos Estados. Por outras palavras, a ciência transformou-se num problema cívico, um problema dos cidadãos (...)". (MORIN, 1990: 103)

A saturação dos sistemas utilizados pode ser percebida quando nos deparamos com realidades nem sempre apreensíveis através dos cortes epistemológicos da ciência moderna. Sustentada nos pilares do racionalismo e do determinismo, como fundantes do conhecimento científico, busca estabelecer as regularidades, leis constantes e repetição dos fenômenos, simplificando-os. Para tanto, instaura rupturas epistemológicas entre espírito/matéria, sujeito/objeto, causa/efeito, indivíduo/sociedade, homem/natureza e tantas outras dicotomias necessárias ao próprio processo de produção do conhecimento científico.

Através dos princípios da objetividade, causalidade lógica e generalização, a ciência moderna tende a focalizar os fenômenos através dos claros que apresentam ignorando os indeterminismos, incertezas e acasos como se de fato não existissem. Diante da impossibilidade de serem determinados, são relegados à exclusão, pois não há como atribuir-lhes propriedades universais e nem aprisioná-los em taxionomias.

Essa racionalidade moderna pôs-se como revolucionária erigindo-se em oposição à hegemonia do saber determinado pela igreja no período feudal. Tratava-se, então, de estabelecer a verdade "aqui", em detrimento das verdades emanadas do "além", estabelecidas pelos advogados de Deus na terra. Agora ela se defronta com o questionamento de sua própria hegemonia. Contraditoriamente a ciência moderna tem encontrado soluções para quase todos os problemas da humanidade, fazendo do conhecimento científico uma fantástica força produtiva, entretanto, ainda é o capital na forma de dinheiro, saber, tecnologia e subordinação à lógica do mercado que designa quem pode desfrutar dos progressos alcançados.

Assim, a ciência é tanto benéfica quanto perigosa e paradoxal: quanto mais refinadas são as especialidades mais facilmente se enclausuram em fragmentos; quanto maior o desenvolvimento científico, maior também a possibilidade da inconsciência, isto é, a própria ciência não tem conhecimento de si pois,

\footnotetext{
"qualquer ação humana, a partir do momento em que é desencadeada, escapa das mãos do seu iniciador e entra no jogo das intenções múltiplas próprias da sociedade, que a desviam da sua finalidade eque, por vezes, lhe dão um novo sentido contrário do que era visado". (MORIN, 1990: 99)
}

Parece paradoxal também que, simultaneamente ao progresso científico, assiste-se ao crescimento do fascínio pelo fantasmagórico, à proliferação dos fundamentalismos, manipulações genéticas, genocídios, racismos; à expansão das seitas religiosas, misticismo, revelações, aparições maravilhosas. Do mesmo modo, não há como se negar que as formas totalitárias de governo, entre as quais o nazismo, foram resultado vitorioso do desenvolvimento da razão apoiada na ciência moderna. Esses são alguns dos inequívocos sinais da existência de outras racionalidades que não são contempladas pela epistemologia cientificista. $O$ homo científicus, sociológicus, filosóficus, se depara com o homo demens, o seu estranho oriundo das pulsões subjetivas que fica alojado nas zonas obscuras e impenetráveis, ${ }^{1}$ mesmo porque se não for olhado não será visto, mas é nesse espaço de invisibilidade que pode residir o covil da opressão. Há sempre algo que escapa ao domínio do logos.

Para entender o homem e a vida em sua unicidade no ecossistema, na cultura social, uma nova epistemologia passa a figurar entre os desejos de uma parcela da comunidade científica, postulando o entrecruzamento da natureza com a cultura, contando inclusive com a interveniência dos processos que escapam à qualquer operação quantificável, processos esses relativos à esfera do imaginário ou noosfera.

\section{"Quero dizer que o conflito, a desordem, o jogo não são escórias ou anomias inevitáveis, não são resídu- os a reabsorver, mas constituintes-chave de toda exis- tência e organização social. Isto é que se deve tentar epistemológicamente conceber" (MORIN, 1990:87).}

Incumbe, então, não rejeitar o paradigma cartesiano mas engajá-lo em permanente interação com a lógica complexa que contemple áleas e improbabilidades acontecimentais. A unicidade entre razão, emoção, inteligência/fé, análise/intuição, homem/natureza/cultura ainda está longe de ser alcançada, contudo as aporias estão postas. Para Morin, "o real é o que resiste à racionalização" e instiga o desejo de uma dialógica metatransdisciplinar entre os domínios lógico, biológico, antropológico, simbólico, sociológico, histórico, cultural que compõem a existência humana.

Habermas já havia se preocupado com esta questão propondo a Teoria da Ação Comunicativa, através da qual advoga o abandono do paradigma da relação sujeito-objeto pela relação interativa que se verifica entre sujeitos na comunicação cotidiana. Conforme Rouanet, para Habermas, embora a indústria cultural e a razão instrumental venham produzindo intensa perda de liberdade,

" a intersubjetividade comunicativa sobrevive, oferecendo reservas intactas de racionalidade espontânea, baseada nos processos de que se dão no mundo vivido" (HABERMAS, apud Rouanet, 1988:141)

Crise, razão e barbárie caminham juntas. Hoje nos defrontamos com monstruosidades espoucando nos mais diferentes espaços sociais do espaço global. Barbáries nada justificáveis e certamente indicativas do estado crítico que vivenciamos.

"Devemos saber que a ciência e a razão não tem a missão providencial de efectual a salvação da hu- 
manidade, mas que têm poderes absolutamente ambivalentes no que diz respeito aos futuros desenvolvimentos da nossa humanidade." (MORIN, 1990: 97)

As incertezas, crises e dilemas estabelecidos não podem ser reputados, por inteiro, à natureza da racionalidade que preside o fazer científico hodierno, contudo é essa razão que se ensina nas escolas, especialmente nas sociedades onde a escolarização é obrigatória. Nessa direção é oportuno ter em conta a reflexão de Adorno.

"Para a educação, a exigência que Auschwitz não se repita é primordial. (...) Justificá-la teria algo de monstruoso em face da monstruosidade que ocorreu. Mas que a exigência e os problemas decorrentes sejam tão subestimados testemunhas que os homens não se compenetraram da monstruosidade cometida. Sintoma esse de que subsiste a possibilidade da reincidencia, no que diz respeito ao estado de consciência e inconsciência dos homens. Todo debate sobre parâmetros educacionais é nulo e indiferente em face deste - que Auschwitz não se repita. Foi a barbárie à qual toda educação se opõe". (ADORNO, in COHN, G. [org.], (1986: 33).

Não há como falar em neutralidade e isenção de culpa. A escola situa-se no centro dramático de todas as tentativas de manutenção e subversão das hegemonias históricas. Para nós, professores, isso constitui uma tragédia e, ao mes-. mo tempo, um espaço de enfrentamento a todas as formas de controle para conseguir a submissão. Auschwitz é sempre uma possibilidade. $\mathrm{O}$ que pode adiar essa possibilidade e tantas outras formas de barbárie praticadas cotidianamente, é a educação. Mas uma educação para formar "gente" orientada pela solidariedade, compreensão do outro, que supere a ética da razão instrumental. Uma educação que seja hostil à cegueira social e a banalização das tragédias humanas, que possibilite a desobediência aos propósitos espúrios dos príncipes da modernidade. Para Auschwitz, Candelária, Eldorado de Carajás, etc... se concretizarem foi preciso a presença submissa e cega daqueles que aceitaram executar as ordens. Ainda que a escola possa não ter qualquer envolvimento direto com isso, tais fatos instalam a impossibilidade da sua omissão.

A escolarização se efetiva, então, como uma decorrência das concepções de ciência, homem, sociedade e cultura que prevalecem em dado momento histórico, pondo-se como ideológica no sentido de idéia-lógico-formal. Afirmar que essa racionalidade escolar não conduz a nenhum lugar é falacioso. Numa sociedade dividida entre quem tem e quem não tem, onde a cidadania obedece a lógica da apartação social, talvez seja essa racionalidade que melhor se ajusta aos fins da dominação. A reapropriação social da escola como instância de humanização e ominização implica em constante reflexão a respeito da natureza e do sentido da ação docente sobre os alunos. Esse repensar envolve a própria cotidianidade do fazer pedagógico. Ali, no espaço microssociológico, ensinamos não só os conteúdos como também componentes atitudinais, emocionais, afetivos - amor, ódio, solidariedade, indiferença.

Voltando à racionalidade escolar, é necessário observar como se organizam as práticas pedagógicas na tentativa a presença da razão instrumental. Nas práticas escolares cotidianas, as rupturas epistemológicas são ainda mais visíveis, a começar pela desconsideração dos saberes constituídos a partir das interações no universo sócio-cultural que são carreados para o interior das escolas, passando pelas relações que são tecidas dentro da própria escola. A parcelização, compartimentalização e hierarquização das atividades didático-pedagógicas traduzem a lógica cartesiana na especificidade da escola. Pode-se alegar que é impossível mudar essa ordem das coisas, pois o processo de transmissão e apropriação do conhecimento demanda essa organização para atender as etapas do conhecimento biopsicológico da criança. Isso é verdadeiro. Mas também é verdade que os atores sociais, sejam eles crianças ou não, constituem-se como sujeitos datados, situados culturalmente e intersubjetivamente enraizados no todo social. A racionalidade escolar opera rupturas epistemológicas onde não há ruptura ontológica. Entre o mundo cultural com todos os saberes do senso comum e o fazer escolar põe-se o bisturi epistêmico, fazendo brotar o descompasso entre escola e sociedade.

Aqui se coloca a questão do método científico e do método de ensino. A pedagogia, enquanto teoria da educação, preocupa-se com o processo de apropriação do saber historicamente acumulado pela sociedade, bem como com a reflexão sobre outros meios necessários para garantir a efetividade dessa finalidade. A didática trata fundamentalmente dos métodos através dos quais se realiza o processo ensino-aprendizagem, caso em que os métodos estão diretamente ligados às especifidades dos conteúdos. Não há como abstrair pedagogia e didática do espírito que predomina no fazer científico como um todo. De certo modo, somos reféns da razão instrumental. Ressalvadas as tentativas de superação por meio de propostas alternativas de educação, ${ }^{2} \mathrm{o}$ formalismo ainda prevalece, pois quase tudo, desde os conteúdos até os comportamentos que são exigidos, está previamente estabelecido e instituído.

$\mathrm{O}$ que se coloca como instituinte é descartado pois escapa à mecânica da previsibilidade didático-pedagógica. Não se pretende retirar a pertinência do planejamento e organização das atividades, mas isso não pode ser um fim em si mesmo, isto é, a flexibilidade dos planos tem que ser efetivamente praticada e não como mera formalidade discursiva. Na escola racionalizada, a única forma de sobreviver é aderindo a ela. Tal como em Durkheim as regras são exteriores, coercitivas e não podem ser modificadas.

A proximidade da epistemologia da educação com a epistemologia das ciências humanas e sociais ${ }^{3}$ não conduz, necessariamente, ao diálogo, pois a divisão entre as ciências produz clausuras, embora responda à incapacidade humana de apropriação das complexidades do real. Cada ciência guarda especifidades metodológicas próprias mas que a unifica (e as separa também) é a pretensão de produzir certezas absolutas isoladas entre si quando tratam do humano que é síntese de onde emergem novas possibilidades. ${ }^{4}$ 
A ênfase na cognição asséptica que caracteriza o sistema de ensino tem se defrontado com suas antinomias. No Brasil, a persistência de altas taxas de evasão e repetência escolar são, desde os anos 30 , um desafio a ser enfrentado; o crescimento das queixas de professores quanto aos comportamentos indisciplinados, rebeldes e desrespeitosos manifestados por alunos, bem como as apatias, indicam que os estudantes estão, a seu modo, questionando o próprio fazer pedagógico. ${ }^{5}$ Os rebeldes e indisciplinados exteriorizam suas inquietações chegando, às vezes, ao confronto. Há aqueles que, na impossibilidade de rejeitar a sistemática escolar, persistem no silêncio, demonstrando aparente aceitação, para sobreviverem no interior do aparato escolar.

Esses comportamentos, entre outros, indicam a existência de verdadeiros flancos de luta contra a hegemonia de um ensino que perdeu o sentido, tornando-se inverossímil, impermeável, não desejado e, por consequiência, não pode ser incorporado na experiência profunda dos escolares. Coloca-se, quando muito, como adição, memorização decorativa, mas não como pertencimento autoreflexivo que adere ao corpo e à inteligência, inclusive na dimensão emocional entendida como capacidade de movência. O Behaviorismo exemplifica bem essa situação. Durante os anos 60 e 70, foi a corrente da psicologia que mais diretamente exerceu influência no âmbito escolar. A seu respeito, Goleman assim se pronuncia:

\begin{abstract}
"A excessiva ênfase da psicologia na cognição mesmo no campo das emoções deve-se em parte, a um acidente na história dessa ciência. Durante as décadas de meados deste século, a psicologia acadêmica foi dominada por behavioristas nos moldes de B.F. Skinner, para os quais só o comportamento que podia ser visto objetivamente, de fora, podia ser estudado com precisão científica. Os behavioristas decretaram toda a vida interior, inclusive as emoções, interditada à ciência". (GOLEMAN, 1996: 52)
\end{abstract}

Sem adentrar na discussão sobre a pertinência positiva ou não dessas manifestações que são opostas à e na escola, pode-se afirmar que, de modo geral, elas atestam o caráter dialético da atividade escolar e, mais precisamente, instalam a crise, o desequilíbrio, desordenam para mostrar que há outras razões, outros desejos para os quais a filantropia pedagógica não basta, assim como não basta a racionalidade asséptica, desprovida das emoções, dos sonhos porque tende a desumanização.

A racionalidade instrumental faz da escola o lugar onde o burocrático sobrepuja o pedagógico-cultural, um espaço de aplicação de políticas educacionais que, sob o pretexto de formar para o mercado de trabalho, secundariza a formação humana. A cada nova política educacional, tudo parece começar do ponto zero, as boas experiências passadas são descartadas em nome de novos métodos, novos objetivos, novas propostas político-pedagógicas. O passado é destituído de significados em favor de novidades que, embora não sejam assimiladas passivamente pelos professores, prejudicam a construção da organicidade no espaço microssocial da escola. De outro lado, é preciso ressaltar que a dinâmica sócio-escolar é constituída de resistências à mudanças, a própria formação dos professores parece desenvolver-se por modelos fixos, isto é, não há espaço adequado para se refletir sobre as experiências passadas que estão no presente e as necessidades postas no sentido de eliminar o descompasso entre escola e sociedade. Daí a suscetibilidade à instrumentalização da escola em relação as políticas educacionais estatais. O exemplo mais atual e acabado dessa instrumentalização é representado pela proposta de "qualidade total". Ela constitui uma séria tentativa de aplicação dos procedimentos empresariais no campo pedagógico e, jogando com recursos emocionais, visa seduzir adeptos para concretizar uma educação atrelada basicamente aos princípios da produtividade e lucratividade; a racionalidade técnica é a própria dominação da "missão civilizatória" do capital.

Disso resulta a necessidade de atentar para a dialética que se estabelece entre passado e presente no cotidiano escolar, bem como na direção de um preparo mais voltado para o entendimento do campo emocional que também passa a ser instrumental para a manutenção dos interesses hegemônicos.

Em resumo, pode-se afirmar que há um clima de desencanto e incerteza quanto ao futuro e uma insatisfação quanto ao presente. Entre algumas espécies não-humanas, quando a sobrevivência está ameaçada, há o desenvolvimento de estratégias sociais capazes de preservar a vịda. DAMÁSIO (1996), explica:

"Essas estratégias ter-se-iam manifestado naquelas, em número limitado, cujos cérebros estavam estruturados para permitir o seguinte: primeiro, uma grande capacidade para memorizar categorias de objetos e acontecimentos e objetos únicos, isto é, estabelecer as representações dispositivas de entidades e acontecimentos no nivel das categorias e no nivel da singularidade; segundo uma grande capacidade para manipular os componentes dessas representações memorizadas e para modelar novas criações por meio de novas combinações. A variedade imediata mais útil dessas criações consistia em cenários imaginados, na antecipação dos resultados das ações, na formulação de planos futuros e na criação de novos objetivos que melhorassem a sobrevivência; e terceiro, uma grande capacidade de memorizar as novas criações acima referidas, isto é, os resultados antecipados, os novos planos e os novos objetivos. Chamo a essas criações memorizadas 'memórias do futuro'". (DAMÁSIO, 1996: 293)

Sobrevivência em risco é situação limite, talvez não seja este o caso da escola pública estabelecida, entretanto há muita insatisfação. Por isto o exemplo extraído da Etologia passa a ter um significado precioso no sentido de refazer as experiências escolares que marcaram o passado para ressignificar o presente projetando o futuro.

A educação escolar, segundo esse propósito, passa a ser entendida como um movimento intencional (perpassado por momentos ou flashes de não-intencionalidade), levado a efeito num contexto histórico como uma prática mediadora 
que tem na realidade sócio-cultural seu ponto de partida e de chegada. É no cruzamento entre uma prática pedagógica assim caracterizada, com uma sociologia que privilegia os sujeitos sociais e uma história cultural onde os homens, mulheres, jovens e crianças são produzidos e produtores que situo a possibilidade de inserir os trabalhos de memória social no campo escolar.

\section{PARTE - MEMÓRIA E EDUCAÇÃO: SUBVERTENDO A RACIONALIDADE ESCOLAR}

\begin{abstract}
"O DIONÍZIO NIETZSCHENIANO, O DEUS DO INSTINTO E DA FESTA, MORRE A CADA DIA NAS ESCOLAS; SUFOCADO POR SÓCRATES 'O HOMEM TEÓRICO’ “. (Jean Claude Forquin)
\end{abstract}

Minha intenção, neste momento do presente ensaio, não ultrapassa a tentativa de trazer à tona mais uma possibilidade de repensar o formalismo e a racionalidade escolar hegemônicos, introduzindo nas práticas pedagógicas atividades que envolvem os próprios escolares no processo de recuperação e registro das memórias inscritas no cotidiano pretérito da escola e do universo cultural inclusivo. Trata-se de uma alternativa que associando ensino e pesquisa com o envolvimento direto da criança-escolar na investigação histórico-social, busca desenvolver tanto a curiosidade em relação aos bens culturais que lhes são próximos, quanto incluir nas práticas escolares os relatos orais de "velhos" personagens que no cotidiano edificam histórias paralelas aos grandes acontecimentos, instalando o diálogo entre criança e velho.

Do ponto de vista do currículo escolar formal, atividades dessa natureza podem tornar as aprendizagens mais significativas pois, os textos didáticos tendem a identificar o passado com coisas mortas e homogêneas. Ao contrário, o passado é plural, sobrevive no presente e este ilumina aquele. Há vida, testemunhas, raízes e fragmentos que precisam ser revelados para repensar a relação ideológica que a própria escola mantém com a história dos vencedores e do poder.

Uma pedagogia que discrimina a sabedoria e as experiências acumuladas pelos velhos reedita acriticamente o que prevalece a nível macrossocial, a opressão e o silenciamento daqueles que esgotados em suas capacidades laborativas transformam-se em pesados fardos para a contabilidade capitalista.

\footnotetext{
"A função social do velho é lembrar e aconselharmemini moneo - unir o começo e o fim, ligando o que foi e o porvir. Mas a sociedade capitalista impede a lembrança, usa o braço servil do velho e recusa seus conselhos. Sociedade que, diria Espinosa, 'não merece o nome de Cidade, mas o de servidão, solidão e barbárie', a sociedade capitalista desarma o velho mobilizando mecanismos pelos quais oprime a velhice, destrói os apoios da memória e substitui a
}

lembrança pela história oficial celebrativa". (CHAUI, M. In: BOSI, E. 1994: 18)

\subsection{Aprendendo o valor da memória com as sociedades sem escrita}

Nas chamadas sociedades primitivas, a educação é realizada no conjunto das relações sociais concretizando-se como processo de transmissão e apropriação da cultura que constitui o grupo social. Malinowski (1984), estudando os nativos de Trobriand (arquipélago situado a noroeste da Nova Guiné), notou que eles costumavam reunir-se em certos finais de tarde para se divertirem. Nessas ocasiões convidavam um homem, entre eles, para contar uma história apresentando determinada performance capaz de agradar e provocar o riso. Diferentes histórias eram contadas em diferentes períodos. Cada história tem seu "proprietário" que pode ensiná-la a outro, autorizando sua narração, entretanto as mais importantes são "propriedades" dos velhos, cujas narrativas são perpassadas de indagações postas pelos jovens interessados nas novidades do presente como "os novos costumes, as novas comunidades, paisagens".

\begin{abstract}
"Os mais velhos e mais experientes fornecer-lhes-ão informações e farão comentários, o que reveste sempre a forma de uma narrativa concreta. Um velho contará talvez as suas próprias experiências sobre combates e expedições, sobre magias famosas e extraordinários empreendimentos econômicos. Com isto, pode misturar as reminiscências do seu pai, contos e lendas de que ouviu falar e que passaram por muitas gerações". (MALINOWSKI, 1984: 107-108)
\end{abstract}

É importante reter que as lendas, mitos e experiências vividas não teriam a mesma significação e nem despertariam o interesse dos nativos se fossem estudados só no papel, desligados da pessoa que narra, do modo como se expressa e do contexto no qual o texto está enraizado. Nessas sociedades a memória oral é um elemento pedagógico através do qual se processa a transmissão cultural que confere identidade a vida aos grupos. Quando os guardiões dos saberes sociais narram, não desempenham o mesmo papel do mestre-escola que aparece somente nas sociedades de escrita. Eles são personagens que tecem os fios entre passado, presente e futuro por meio da transmissão dos conhecimentos práticos, técnicos e dos saberes que presidem a vida societária.

O que é válido para as sociedades sem escrita não pode ser aplicado às sociedades históricas. Assim, longe de fazer qualquer apologia ao saber oral nativo como fonte de "imortalidade social", faz-se necessário relativizar a força da tradição oral que, em nossas sociedades, deve estar ao lado da experiência de transmissão do conhecimento pela escrita. Nessa direção a memória oral pode constituir-se em elemento didático-pedagógico necessário a formação para a formação das identidades sociais.

Marcel Mauss (1974), analisando o modo como diferentes povos concebem a idéia de pessoa, verificou, por 
exemplo, a presença entre os índios Zuni, de determinado número de sujeitos nominados que ocupam, por posição de nascimento, certos lugares na ordem social e simbólica da tribo, isto é, os nomes são obtidos por direitos descendência de um ancestral verdadeiro ou imaginário. Os herdeiros dessas nominações constituem-se em espécies de homensmemória que, através das máscaras dos antepassados, usadas nos rituais coletivos e nas danças, presentificam e dão vida aos mortos, preservando simbolicamente a própria vida social. A simbologia do antepassado é assumida e se reencarna no indivíduo que carrega o nome do ancestral.

Mauss, refere-se ainda aos Kwakiutl que atribuem dois nomes para cada sujeito nobre do clã, um para o verão e outro para o inverno, um sagrado e outro profano. À medida em que o menino cresce seu nome muda, pois varia também a posição social que ocupa no grupo. Mais do que o eu próprio, o indivíduo é personagem que ao incorporar a nominação do antepassado, simbolicamente reúne morte e vida. A cultura através do exercício contínuo da memória refaz a cadeia entre mortos e vivos. É o segundo nome que suplantando o primeiro, perpetua a memória de um ancestral, exercendo a função de veneração e consolidando a identidade coletiva fundada em certos mitos de origem. Os saberes são transmitidos por fórmulas práticas fortemente ligadas à magia religiosa.

Pierre Clastres (1978) reportando-se ao papel da "tortura nas sociedades primitivas", lembra inicialmente que a difusão da escola gratuita e obrigatória constitui, entre nós, um dos meios mais recentes e eficazes de conservar sempre presente a dureza da lei, impossibilitando qualquer alegação de desconhecimento. Entretanto, as formas de escrita diferem de sociedade para sociedade, de tal modo que mesmo entre certos povos ágrafos o poder da lei era gravado em pedras e árvores na forma de pinturas ou tatuagens corporais. Os ritos de iniciação provocando chagas, visavam ensinar e inscrever nos corpos dos jovens, através da dor e do sofrimento, a memória do pertencimento social.

"O objetivo da iniciação, em seu momento de tortura, é marcar o corpo: no ritual iniciatório, a sociedade imprime a sua marca no corpo dos jovens. Ora, uma cicatriz, um sulco, uma marca são indeléveis. Inscritos na profundidade da pele, atestarão para sempre que, se por um lado a dor pode não ser mais do que uma recordação desagradável, ela foi sentida no contexto de medo e de terror. A marca é um obstáculo ao esquecimento, o próprio corpo traz impresso em si os sulcos da lembrança - o corpo é uma memória. Pois o problema é não perder a memória desse segredo confiado pela tribo, a memória desse saber de que doravante são depositários os jovens iniciados" (CLASTRES, 1978: 128)

A memória da lei marcada sobre o corpo torna inesquecível a pertença social repondo a impossibilidade do desejo do poder e, contraditoriamente, também da submissão. Evoca ainda a igualdade de todos na tribo e a consciência da continuidade da vida tribal.

O que se quer ressaltar aqui é o valor pedagógico da tradição oral. Nas sociedades ágrafas os velhos são respeita- dos e necessários à manutenção da harmonia e coesão social. É essa tradição que nosso sistema escolar bloqueia. A relevância atribuída ao modo de narrar, nas chamadas sociedades primitivas, nos remete a entender como Lovisolo (1989) que

"Poucos professores são capazes hoje de contar histórias embebidos pelo animus narrandis, embargados pelo prazer de recordar as datas, os personagens, os fatos, as ações". (LOVISOLO, 1989: 19)

É importante fixar que as sociedades sem escrita se orientam pelos princípios estruturantes da tradição e, por conseqüência, a memória aparece como suporte de um devir que implica numa práxis coletiva direcionada para a estagnação. A diferença está em que as sociedades históricas se orientam pelo princípio estruturante da transformação por superação dos valores passadistas. Aqui a memória aparece como processo de refazimento do passado orientado pelos valores, necessidades e referências do presente visando a reelaboração do devir histórico.

A heterogeneidade dos grupos sociais, diversidade cultural e valórica que caracterizam as sociedades complexas emergem apenas como elementos secundários no saberfazer da escola formal pois, a regularidade de suas práticas e dos comportamentos estabelecidos como desejáveis, efetivam-se a partir dos paradigmas das classes sociais dominantes que inventam tradições para ocultar as diversidades e conflitos. Assim, na pedagogia a história escrita se torna o meio por excelência do ensino escolar, entretanto deveria ser um dos modos de ensinar, mesmo porque a memória convive com a memória escrita fazendo parte da vida cotidiana.

A escola, em sua formalidade, limita-se à transmissão oral da cultura letrada realizada por especialistas-professores que nem sempre atentam para a riqueza das experiências vividas e encarnadas nas pessoas, especialmente nos velhos que carregam em seus corpos as marcas do trabalho $\mathrm{e}$ dos fatos vividos na pluralidade dos grupos sociais que configuram memórias coletivas heterogêneas.

O professor pode ser ele mesmo uma memória viva do trabalho educativo que circula na espaço escolar e não se constitui como elemento pedagógico. A escola é, então, um campo cultural onde há a movimentação de mitos, crenças, desejos e aspirações. Um espaço de vivências sociais que a racionalidade instrumental não consegue penetrar, já que se compõe de redes simbólicas que resistem a racionalização e no entanto configuram a realidade. Tornar o passado escolar inteligível à luz do presente significa compreendê-lo para que não se repita como sucessão de erros; significa instalar a memória crítica para quebrar a imagem ideológica de um passado e presente homogêneos. É exercício de auto-reflexão que, longe de ser somente uma memória individual, porque todos somos memorialistas, põe-se como elaborações experienciadas por grupos sociais radicados nos mais diferentes espaços escolares, vez que se colocam como lugares de sociabilidade e de trabalho por onde circulam memórias de grupos.

“O ano acabado, os alunos se dispersam, e essa classe definida e particular não se reorganiza nunca mais. 
(...) Para os alunos, ela viverá por algum tempo ain$d a$; pelo menos, a ocasião freqüentemente se lhes oferecerá para nela pensar, e dela lembrar-se. Como eles têm quase a mesma idade, talvez pertençam aos mesmos meios sociais, não esquecerão que estiveram próximos sob os cuidados do mesmo mestre. As informações que este lhe comunicou levam a sua marca; frequientemente, quando nelas repensarem, através e além desta noção, perceberão o mestre que lhes revelou, e seus companheiros de classe que as receberam ao mesmo tempo que eles. Para o mestre, será completamente diferente. (HALBWACHS, 1990: 29)

\subsection{A propósito da relação entre memória (escolar) e história (da educação)}

A primeira noção que se associa à palavra memória é a de inteligência como capacidade de compreensão, de reter fatos ou idéias como um arquivo que a cada estímulo pode reler aquilo que está impresso. Nesse sentido, a memória artificial é a extensão da capacidade humana de retenção das informações. Contudo, ainda que o progresso científico e tecnológico venha produzindo artefatos cada vez mais sensíveis, o homem permanece como o único depositário que é capaz de viver e arquivar percepções sensoriais e impressões dos fatos experienciados, bem como, reinterpretá-los à luz de estímulos que ensejam as lembranças ou mantém os esquecimentos.

A indústria cultural tenta homogeneizar as consciências sociais e a historiografia oficial faz crer que não existe memória popular. No entanto, como a memória é a única das faculdades humanas que não pode ser apropriada por outrem sem consentimento, ela torna-se um refúgio onde estão alojados os acontecimentos que escapam à lógica da cristalização histórica porque é seletiva e passa pela análise da diferença, lembranças e esquecimentos. Através da memória se elimina a petrificação do passado, para situar a história nos locais onde os sujeitos existem exercendo suas práticas sociais que, longe de serem homogêneas, constituem-se como reinterpretações e releituras do passado à luz das circunstâncias presentes.

A própria história escrita, ainda que ideológica, é ela mesma uma memória, podendo ser reveladora de outras memórias que irrompem dos interditos daquilo que está escrito. Mesmo assim é necessário estabelecer a diferença que existe entre memória e história. De acordo com Edgar de Decca, para Pierre Nova,

"A memória é a vida, sempre guardada pelos grupos vivos e em seu nome, ela esta em evoluções permanentes, aberta à dialética da lembrança e do esquecimento, inconsciente de suas deformações sucessivas, vulnerável a todas utilizações e manipulações, suscetivel de longas latências e súbitas revitalizações. A história é reconstrução sempre problemática e incompleta daquilo que já não é mais. A memória é fenômeno sempre atual, uma ligação do vivido com o eterno presente; a história é uma representação do passado.
Porque ela é afetiva e mágica, a memória se acomoda apenas nos detalhes que a conformam; ela se nutre de lembranças vagas, telescópicas, globais ou flutuantes, particulares ou simbólicas, sensivel a toda transferência, censura ou projeção. A história porque operação intelectual e laicizante, exige a análise e o discurso crítico. A memória se enraiza no concreto, no espaço, no gesto, na imagem e no objeto. A história não se liga a não ser em continuidades temporais, nas evoluções e relações de coisas. A memória é um absoluto, história não conhece mais do que o relativo. No coração da história trabalha um criticismo destruidor da memória espontânea. A memória é sempre suspeita à história, donde sua verdadeira missão é a de destruí-la e de rechaçá-la". (NORA, P. apud de Decca, 1994: XIX, XXX).

Para de Decca, a sociedade atual tende a destruir os vínculos coletivos refinando cada vez mais o individualismo e destruindo, pouco a pouco, as bases da memória espontânea. Em face da possibilidade de uma perda definitiva do passado e da fugacidade do ser humano, criam-se centros específicos que guardam a memória, arquivando-a. O direito ao passado reivindicado por grupos e pessoas transforma-se, então, numa armadilha que, ao invés de conservar a memória como história vivida, petrifica-a na forma de banco de dados, cujos usos nem sempre perseguem interesses éticos. Aqui se coloca a questão da utilização que se faz da história escrita a fim de silenciar a memória popular, traçando e legitimando certos vínculos de identidade com os dominantes. Daí a necessidade de buscar a "memória menos nos textos e mais nas palavras, imagens, gestos, rituais, festas". Enquanto a história se desenvolve como rememoração, a memória social pode surpreender pois, quando flui em sua dimensão crítica, mostra seu potencial libertador.

De outro lado, memória como saudosismo e idealização nostálgica do passado é servidão e apego a um passado que é e está mas não pode ser revificado. Embora pertença aos indivíduos, a memória é coletiva porque faz parte de uma trama social mais ampla. Os indivíduos nunca estão sós porque fazem parte de um tempo e espaço social. Não existe, contudo, uma memória coletiva e única e sim muitas em conformidade com a noção de pertencimento concretizada por diferentes grupos sociais. A evocação de uma memória coletiva única coloca-se como tentativa de manipulação cultural que as classes hegemônicas intentam a fim de escamotear a existência de memórias antagônicas. A escolaridade e o trabalho docentes são materializados em tempos e espaços sociais historicamente determinados e nos quais são tecidas redes de sociabilidade. Embora a instituição escolar tenha merecido muitos estudos, paradoxalmente ainda é pouco conhecida. Para PAOLI (1992),

"A construção de um outro horizonte historiográfico se apoia na possibilidade de recriar a memória dos que perderam não só o poder, mas também a visibilidade de suas ações, resistências e projetos (...). Aposta, portanto, na existência de memória coletivas que mesmo heterogêneas, são fortes referências 
de grupo mesmo quando tenha um fraco nexo com a história instituída. É exatamente aí que se encontra um dos maiores desafios: fazer com que experiências silenciadas ou privatizadas da população se reencontrem com a dimensão histórica". (PAOLI, 1992: 27)

Os historiadores da Educação exploram a documentação do passado buscando reconstruir o fazer pedagógico em abordagens tendentes a generalizações e a partir de matrizes interpretativas mais ou menos lineares que, nem sempre, contemplam a diversidade do fazer escolar. Trazer à luz a memória da educação escolar que está inscrita não só nos documentos mas também nos professores, alunos, nas relações que são tecidas nas escolas e nos grupos sociais inclusivos, significa a um só tempo, libertar os fragmentos de um passados que está destinado ao esquecimento pela historiografia tradicional da educação e, contraditoriamente, vive no presente de atores anônimos que, de fato, constróem a história da escolarização. O passado tem mais a nos dizer do que aquilo que consta escrito e sistematizado porque sobrevive no presente.

Diante disso, importa salientar que a história da educação passa a ser um sub produto da história geral e, nesse campo específico, a educação formal que se processa, por exemplo, no meio rural, torna-se mero apêndice pois, a exclusão social a que foram submetidos os humanos do campo, corresponde também à exclusão desse segmento social da própria historiografia.

Se quisermos entender melhor a instituição em sua heterogeneidade é preciso ir ao seu encontro na tentativa de traduzir o múltiplo movimento de usos e práticas que os atores escolares constituem na concretude do trabalho escolar. $\mathrm{Na}$ escolarização brasileira pouco sabemos sobre a materialidade das práticas pedagógicas pretéritas, seus efeitos e possíveis contribuições na configuração e legitimação de certos movimentos políticos, tal como o nacionalismo.

Recorrer à memória escolar pode ser um recurso fundamental para revelar a tessitura dessas relações e o modo como se dá a elaboração simbólica relativa à estrutura da escola, bem como, o lugar que ocupa no espaço e tempo em que se situa. Forquin, lembra que:

"a reflexão pedagógica contemporânea não poderá contornar a questão da modernidade nem se resignar em fazer a apologia da amnésia, pois só uma visão extremamente superficial e prematura da modernização do mundo pode nos fazer aderir ao mito do efêmero e rejeitar, como um fardo, nosso pertencimento à memória." (FORQUIN, 1993: 20).

A escola, como lugar de sociabilidade, é simultaneamente suporte de memória e obra de memória, contudo os métodos de ensino parecem ignorar sua positividade pedagógica, enquanto exercício de refazimento do passado pelos dilemas e incertezas do presente. Se é preciso superar a racionalidade asséptica e instrumental que marcam as práticas pedagógicas, porque não ousar enveredando também pelos caminhos tortuosos da memória sócio-escolar.
A moderna pedagogia embasada na

"crítica erudita da memória (...) se opõe: por um lado, à valorização de memória histórica ou coletiva, por outro, à valorização popular da memória, que tem como indicadores (...), a renovação do apelo dos programas de perguntas e respostas, cujos temas, freqüentemente sem valor de uso, parecem evocar um lado lúdico da memória rejeitado pelas pedagogias modernas" (LOVISOLO, 1989: 18).

De fato, a memorização, enquanto capacidade de lembrar é fundante do processo de apropriação do conhecimento, mas isso não deve obstar o desenvolvimento da criatividade, imaginação, capacidade crítico-reflexiva de si e das possibilidades de transformar o que se tornou reiterativo e sem sentido. Entre as memorizações exigidas no conjunto das atividades acadêmicas e a riqueza do universo cultural inclusivo (presente na própria escola), põe-se a pesquisa através de relatos orais, como método de ensino que pode dar sentidos e significados mais compatíveis, particularmente na formação de professores. O poder de seleção da memória docente e a capacidade de esquecimento, bem como, a idéia de que tudo na escola é conservação, ou ainda, os processos de construção e desconstrução das memórias coletivas nos espaços escolares, são questões em aberto.

\subsection{Memória e Ensino: refazendo o acontecido}

Refazer o acontecido é o imperativo da memória e também o imperativo que ora se apresenta. Refiro-me aqui a uma experiência específica que buscou, com relativo sucesso, integrar memória e ensino. A decisão de iniciar uma atividade de recuperação da memória "na" escola e "da" escola surgiu no calor de uma série de outras pesquisas que procuravam inventariar e registrar as marcas deixadas pela cafeicultura na região norte paranaense. Os estudos estavam. concentrados no município de Londrina, mais especificamente, no Patrimônio rural denominado Heimtal, situado ao norte do município.

Como primeiro núcleo de povoamento da cidade, originado no final dos anos 20, o Heimtal abrigou a primeira escola de Londrina. Fundada em 26 de julho de 1931, nasceu impregnada de conteúdo étnico para atender os filhos dos imigrantes alemães ali radicados, por isto ela ficou conhecida como "Escola Alemã". Essas especifidades históricas, associadas à insatisfação quanto ao tratamento didático que tem sido empregado, nas primeiras séries do ensino fundamental, quando se focalizam aspectos da história local, foram fatores que motivaram a ousadia de integrar os escolares na recuperação da memória, valorizando os instrumentos da história oral e os relatos vivos dos atores sociais para compreender as estruturas do cotidiano presente e pretérito.

Por meio de atividades extra-curriculares (o currículo formal não comporta espaço para isso), que reuniam tanto uma dimensão lúdica quanto pedagógica se buscou, primeiramente, sensibilizar a comunidade escolar para o reconheci- 
mento da memória coletiva do bairro e dos bens culturais nele inscritos. Nesse sentido, precisamos lembrar que:

"não há memória coletiva que não se desenvolva num quadro espacial. Ora, o espaço é uma realidade que dura: nossas impressões se sucedem, uma à outra, nada permanece em nosso espírito, e não seria possível compreender que pudéssemos recuperar o passado, se ele não se conservasse, com efeito, no meio material que nos cerca. É sobre espaço, sobre o nosso espaço - aquele que ocupamos, por onde sempre passamos, ao qual sempre temos acesso, e que em todo o caso, nossa imaginação ou nosso pensamento é a cada momento capaz de reconstruir - que devemos voltarnossa atenção (...). (HALBWACHS, 1990: 143)

As primeiras atividades envolveram crianças de terceira a quinta séries, na pesquisa de brincadeiras infantis, jogos e divertimentos que haviam povoado a infância de seus pais, avós e antigos moradores do local. O registro implicou em que certos aspectos desses jogos e brincadeiras fossem encenados pelos adultos, despertando o interesse das crianças no sentido de presentificá-los o que imprimiu ludicidade ao pedagógico. Ainda que não se tenha notado diferenças gritantes entre as brincadeiras coletivas do presente e do passado, foi possível perceber que, no meio rural pretérito, o brincar estava intrinsecamente ligado ao trabalho e à natureza, de onde se retirava a matéria prima para construir os brinquedos: a espiga de milho transformava-se na boneca, a mamona no combustível do estilingue, vegetais ainda pequenos viravam carrinhos mobilizados por elásticos.

Desenhos, poemas e redações revelavam as representações das crianças sobre o próprio bairro, suas edificações, espaços públicos e privados, bem como, as imagens da cidade. Não faltaram críticas às condições objetivas do bairro e nem interpretações bastante intrigantes da cidade, visualizada ora como uma concentração fria de prédios sem a presença da vida humana, ora nos seus espaços utilitário e de lazer. Aqui aparecem sinais da identidade social expressas nas diferenças entre o rural e o urbano, reafirmado em síntese, que a memória tem suporte no grupo limitado em sua espacialidade e temporalidade.

Enquanto a memória assegurar o sentimento de identidade, a história desfaz e põe em crise o próprio sujeito histórico. Para a escola a prática da memória enseja o fortalecimento da identidade do grupo. Entretanto isso não significa indução ao ensimesmamento que, em nome do respeito, produz clausura cultural mas, o desafio de conviver com permanências do passado num presente fluido e conflituoso. A história, ao contrário do que evidenciam os livros didáticos, é uma construção social enraizada no cotidiano, portanto reconstituir esse patrimônio de conhecimento e participação dos grupos sociais (camponeses, índio, etc.) significa resistir ao holocausto cultural que emerge do processo de globalização capitalista.

Quanto à recuperação de músicas antigas, pode-se afirmar que pouco interesse despertam, porém, os contos motivaram ativamente as crianças. Eles assumiram a feição de "casos" que foram recontados e reinterpretados pelos alu- nos. A imaginação infantil mobilizada por este tipo de atividade sugeriu a necessidade de dramatizar o episódio do "lobisomem". Todos nós, adultos, somos sobreviventes de um universo infantil povoado pelo imaginário de fábulas e contos perversos. $\mathrm{Na}$ infância tais contos parecem ser encarados como familiares ainda que provoquem medo e estranhamento. Quando o adulto se remete à infância, na idade da razão, esse passado infantil assemelha-se a um paraíso idealizado. Os casos parecem ser lembrados e recontados às crianças como experiências realmente vividas, embora tenham se configurado na memória através de narrativas dos outros.

A repetição pela tradição oral e, consequiente sobrevivência desses "casos de assombrações" para a infância do presente, é garantida pela significação que eles contêm, por seus efeitos de medo e prazer ou morais simbólicos que, frequientemente, servem para governar o reino infantil.

Ainda que essas atividades privilegiassem a face lúdica do trabalho educativo constituíram-se como um ponto de partida necessário para a inserção de crianças no processo de recuperação e registro da memória da própria escola em que estudavam. Os alunos foram estimulados a desenhar a escola do presente e a do passado. A escola atual foi retratada exatamente como é, contudo quanto à do passado não foi possível retratar porque não era conhecida. Essa impossibilidade suscitou questões que ocuparam o lugar do desenho e compuseram um roteiro prévio de entrevistas. Essa metodologia tornou possível a integração efetiva das crianças em todas, ou quase todas, as etapas da pesquisa. Da curiosidade infantil emergiram dúvidas quanto ao passado que, obviamente, precisa ser revelado.

Nos arquivos da Secretaria Municipal de Educação foram encontrados documentos posteriores ao ano de 1945 , quando a Escola Alemã foi municipalizada, portanto não se dispunha de qualquer informação documental necessária anterior a esse período, tornando imprescindível o recurso da história oral.

A localização dos possíveis informantes mobilizou todos. As crianças indicaram não só antigos moradores do bairro que haviam sido alunos da escola, ainda em seus primórdios, nos anos 30, como também velhos professores residentes em outras localidades. Várias sessões de entrevistas foram realizadas com as crianças reunidas em grupos. Nessas ocasiões elas formulavam questões aos informantes mantendo a atenção voltada para os narradores. $O$ gravador serviu como elemento organizador e provocador de novas questões, às vezes inusitadas, que não estavam contidas no roteiro.

Para além de uma versão e uma visão somente individual, os relatos orais revelavam histórias da infância vivida especialmente na escola porém, sem desconsiderar o ambiente que nele encerra elementos constitutivos da sociedade mais ampla. Os narradores da experiência escolar passadista, enfocaram aspectos que traduziram o modo de ensinar, as relações que eram travadas entre alunos e professores, as brincadeiras e artimanhas que costumavam realizar. Quando instigados a relembrar dos castigos e reprimendas, pareciam justificar a necessidade dos mesmos, amenizando-os. $\mathrm{O}$ esquecimento da dor moral e física resul- 
tante de permanecer com os braços abertos de frente para a parede ou de ajoelhar em tampinhas e grãos de milho, faz parte da idealização do passado. $\mathrm{Na}$ verdade é um retrato imagético ressignificado por um presente escolar no qual a autoridade do professor é posta em desequilíbrio. No presente os castigos e reprimendas são proibidos por isto, o caráter seletivo da memória escolar implica na reinterpretação ou esquecimento dos aspectos considerados reprováveis no presente.

Houve também referências constantes aos objetos escolares do passado, por isto organizou-se uma gincana com o objetivo de reunir na escola, elementos capazes de retratar com maior vivacidade e fidelidade, o modo de ser e de estudar pretérito, abrindo a possibilidade para que, as crianças em diálogo com seus pais, avós e conhecidos, refizessem o modo de brincar na escola e fora dela, construindo os brinquedos característicos de outros tempos.

As relações não ficaram restritas somente ao cotidiano escolar, mesmo porque a escola não está imune às influências das políticas macrossociais. Os informantes retiramse, com certa dose de tristeza, ao fechamento da Escola Alemã, no período da segunda guerra mundial. Essa relação entre a parte e o todo ficou mais evidenciada para as crianças que participaram do experimento, quando através das relações instalou-se um diálogo que extrapolou o mero ouvir pois as emoções foram explicitadas, demonstrando as formas como as políticas educacionais são concretizadas e interpretadas no cotidiano.

Esse experimento permite afirmar, por um lado, que o valor pedagógico dos trabalhos de memória está diretamente relacionado a possibilidade de imprimir vivacidade à história escrita. Para além da memorização de palavras insólitas inscritas nos livros, a metodologia de pesquisa transformada em metodologia de ensino possibilita entender a história como construção coletiva enraizada no cotidiano. De outro lado, estabelece condições propícias ao desenvolvimento da capacidade de organização e comparação de fatos e idéias com o necessário registro dos menos. Favorece também a desenvoltura da oralidade e curiosidade histórica.

Certamente a escola não pode se resumir a este tipo de atividades, contudo não pode negar seu valor educativo e pedagógico pois,

"É esse passado vivido, bem mais do que o passado apreendido pela história escrita, sobre o qual se poderá mais tarde apoiar-se sua memória". (HALBWACHS, 1990:71).

\section{III - NOTAS INCONCLUSAS}

Os questionamentos críticos sobre a racionalidade instrumental revelam que as práticas escolares assim modeladas tornam-se impermeáveis e não são encarnadas na experiência profunda das crianças. Entretanto, a escolarização inscreve-se nas biografias compondo parte importante das trajetórias de vida dos indivíduos. Assim sendo, os próprios professores que também vivenciaram a escola na condição de alunos, são verdadeiras fontes vivas da memória escolar. Nessa direção importa estabelecer momentos coletivos, no interior das escolas, com o objetivo de refazer os recursos vividos, exercitando a memória crítica como alternativa para repensar o próprio fazer e seus significados. Trata-se de constituir momentos pedagógicos de refazimento da relação presente/passado escolar pela incorporação de si mesmo e dos outros, na tentativa de desconstruir a noção de que o passado é sempre melhor do que o presente e que este não tem mais jeito.

Inserir trabalhos de memória social no campo do ensino, permite trazer à cena do presente, com o auxílio dos próprios alunos, um passado vivido que pode ser presentificado por velhos atores sociais, geralmente ignorados na relação pedagógica. A exemplo das sociedades sem escrita o exercício da memória oral tanto educa quanto confere concretude aos fatos históricos. Do mesmo modo, os relatos de experiências escolares pretéritos, que não estão inscritos na história da educação, podem se constituir como uma pedagogia que, associando pesquisa ao ensino, torna mais significativo o processo de formação de professores. Em geral os paradigmas que orientam a formação docente cristalizam-se em práticas reiterativas e resultam em resistência à mudanças. Nessa situação, a memória pode ser a mediação para a transformação pois coloca-se como o espelho em que se reconhece as diferenças necessárias ao processo de reinterpretações das rotinas repetitivas.

As crianças-escolares quando estimuladas a recuperar a memória do bairro, da escola e dos bens culturais que lhes são próximos, revelam um entusiasmo acadêmico praticamente inexistente nas atividades formais. Assim a libertação das memórias de velhos atores sociais (alunos, professores, trabalhadores, etc.) por meio de relatos orais, colhidos pelas próprias crianças, é uma, entre muitas alternativas, capaz de ganhar lugar de destaque nas biografias dos alunos. Ainda que as memórias se manifestem através de imagens expressas individualmente, elas se reportam a quadros sociais e temporais mais amplos, possibilitando, do ponto de vista pedagógico, a reapropriação das mesmas como fator de ensino e de aprendizagem.

Essa perspectiva aposta na interação dinâmica entre sujeito gnosiológico e sujeito ontológico, pois no ato de produção das memórias, como história escrita, tornam-se inseparáveis. O que é válido para a construção das relações sociais (produção da memória), torna-se válido para a elaboração de sua representação, científica ou não, vez que supõe a apreensão seletiva e combinação de elementos pelo sujeito narrador. A pedagogia que aí se põe como mediação, entre as memórias expressas a partir das representações desses sujeitos e o trabalho de escrita, não pode se furtar à análise comparativa e interpretação das informações obtidas. Essa é a face mais construtiva de uma prática escolar aberta aos trabalhos de memória, mesmo porque eles possibilitam a configuração de uma verdadeira interdisciplinaridade que supera a justaposição das disciplinas escolares, fundando um centro irradiador das aprendizagens e do ensino. Pode-se objetar sobre a pertinência do envolvimento dos escolares nesse processo, entretanto, desde que saibam ler e escrever nada obsta que participem. Enquanto as pedagogias usuais 
subestimam as capacidades infantis, essa abordagem pode oxigenar o ambiente escolar introduzindo rupturas no seu formalismo e hierarquização pela ousadia de acreditar nas potencialidades infantis.

As dúvidas e incertezas que pairam sobre a validade e consequiências da insistência numa escolarização enraizada na epistemologia cartesiana, implicam no envolvimento das crianças-escolares não somente em atividades de recuperação da memória social, mas também como informantes do cotidiano vivido na escola e fora dela. Nessa direção é importante recorrer à Malinowski quando relata o modo como foi recebido pelos nativos a fim de realizar suas pesquisas.

"Obtive informações preciosíssimas sobre vários as pectos de rapazes e até mesmo de raparigas dos 7 aos 12 anos de idade. Com freqüência, (...) era acompanhado pelas crianças da aldeia e nessa altura, sem a obrigação de estarem sentadas e atentas, falavam e explicavam as coisas com surpreendente lucidez $e$ conhecimento das questões tribais. De facto, várias vezes pude resolver, com ajuda das crianças, dificuldades de natureza sociológica que os homens velhos não eram capazes de me explicar. A facilidade de raciocínio, a ausência da mais leve suspeita e sofisticação, e possivelmente uma certa dose de treino recebida na Escola da Missão, faziam delas excelentes informadores em muitos aspectos. Quanto ao perigo de as suas opiniões serem moldadas pelo ensino missionário, só posso dizer que me surpreendeu a absoluta impermealidade de mente nativa a essas coisas." (MALINOWSKI, 1984: 269) dita primitiva ou arcaica? Que valem os nossos critérios de racionalidade" " (id. ibd. p.24).

5 Ver a esse respeito: PATO, M. Helena de Souza. A produção do Fracasso Escolar: Histórias de submissão e rebeldia. São Paulo: T. A. Queiroz, 1991.

\section{REFERÊNCIAS BIBLIOGRÁFICAS}

ADORNO, T.W. Educação após Awschiwitz. In: COHN, G. (org.). Adorno. Coleção. Grandes Cientistas Sociais (54), Trad. Flávio R. Kothe. São Paulo: Ática, 1986.

BOSI, E. Memória e Sociedade: lembranças de velhos. São Paulo: Companhia das Letras, 1994.

CANETTI, E. O Sobrevivente. In: Massa e Poder. Trad. Rodolfo Krestan. São Paulo: Melhoramentos; Brasília: Ed. Universidade de Brasília, 1983.

CLASTRES, P A Sociedade Contra o Estado: pesquisas de Antropologia política. Trad. Theo Santigo. Rio de Janeiro: F. Alves, 1978.

DAMÁSIO, A. $O$ Erro de Descartes: emoção, razão e o cérebro humano. São Paulo: Companhia das Letras, 1996.

DE DECCA, E.S. Memória e Cidadania. In: O Direito à memória: Patrimônio Histórico e Cidadania. DPH: Secretaria Municipal de Cultura: Prefeitura do Município de São Paulo. São Paulo: DPH, 1992.

DEMARTINI, Z. de B.F. Trabalhando com Relatos Orais: reflexões à partir de uma trajetória de pesquisa. In: Textos $3,2^{\mathrm{a}}$ série. Centro de Estudos Rurais e Urbanos. São Paulo: CERU, 1992.

FORQUIN, J.C. Escola e Cultura: as bases sociais e epistemológicas do conhecimento escolar. Porto Alegre: Artes Médicas, 1993.

GOLEMAN, D. A Inteligência Emocional: a teoria revolucionária que redefine o que é ser inteligente. Trad. Marcos Santarrita. Rio de Janeiro: Objetiva, 1996.

HALBWACHS, M. A Memória Coletiva. São Paulo: Vértice: Editora Revista dos Tribunais, 1990.

LOVISOLO, H. A memória e a formação dos homens. In: Estudos Históricos: Memória, (3), vol. 2, Associação de Pesquisa e Documentação Histórica, Rio de Janeiro: Editora Revista dos Tribunais: Vértice, 1989.

MALINOWSKI, B. Magia, Ciência e Religião. Portugal: Edições 70, 1984.

MAUSS, Marcel. Sociologia e Antropologia. vol. I, trad. Lamberto Puccinelli. São Paulo: EPU, 1974.

MORIN, E. Ciência com Consciência. Portugal: Publicações Europa-América, 1990.

PAOLI, M.C. Memória, História e Cidadania: o Direito ao Passado. In: $O$ Direito à memória: Patrimônio Histórico e Cidadania. DPH: Secretaria Municipal de Cultura: prefeitura do Município de São Paulo. São Paulo: DPH, 1992.

PATTO, M.H. de S. A Produção do Fracasso Escolar: histórias de submissão e rebeldia. São Paulo: T. A. Queiróz, 1991.

POLLAK, M. Memória, esquecimento e silêncio. In: Estudos Históricos: memória (3), vol. 2. Associação de Pesquisa e Documentação Histórica, Rio de Janeiro: Editora Revista dos Tribunais: Vértice, 1989.

ROUANET, S.P. O Olhar Duminista. In: NOVAES, A. et al. $O$ Olhar. São Paulo: Companhia das Letras, 1988. (...). Serve-se de de noções mecânicas e energéticas, das quais, efectivamente, elimina as idéias de actores, de sujeitos". (MORIN, Edgar. Ciência com Consciência. Portugal: Publicações Europa-América, 1990. p.215).

${ }_{4}$ É preciso reter que as ciências humanas emergem num momento em que se pode pensar num espaço subjetivo. A subjetividade neste caso é aquela que se refere ao sujeito que ao investigar um dado objeto, não o faz objetivamente, já que é parte integrante do todo social. Como resultado tem-se a objetividade subjetivada ou uma subjetividade objetivada. Assim sendo, Morin explica: "O sociólogo deve incessantemente perguntar a si mesmo como pode conceber uma sociedade de que faz parte. Já o antropólogo contemporâneo diz de si para di". "Como é que $e u$, portador inconsciente da minha cultura, posso julgar uma cultura 